\title{
Qualitative research in dentistry
}

\author{
K. Stewart, ${ }^{1}$ P. Gill, ${ }^{2}$ B. Chadwick ${ }^{3}$ and E. Treasure ${ }^{4}$
}

\author{
VERIFIABLE CPD PAPER
}

\begin{abstract}
This paper is the first in a series of four that provides an overview of the key elements of qualitative research. In particular, it discusses issues such as what qualitative research is, when its use is appropriate, what it can offer dentistry and approaches to data collection and analysis. Where appropriate, examples of dental studies that have used qualitative methods are also provided for practical purposes.
\end{abstract}

\section{INTRODUCTION}

Research in dentistry has predominantly been quantitative in nature, fuelled latterly by the drive towards evidencebased dentistry. Randomised control trials (RCTs), cross-sectional studies and questionnaire-based surveys are the most common research approaches used., ${ }^{1,2}$ Although now used with increasing frequency in dentistry, particularly in dental public health, ${ }^{2}$ few dental studies have been conducted using qualitative research methods. Consequently,

\section{QUALITATIVE RESEARCH IN DENTISTRY}

1. Qualitative research in dentistry

2. Methods of data collection in qualitative research: interviews and focus groups

3. Conducting qualitative interviews with school children in dental research

4. Analysing and presenting qualitative data

${ }^{1}$ Research Fellow, Academic Unit of Primary Care, University of Bristol, Bristol, BS8 2AA, ${ }^{2 *}$ Senior Research Fellow, Faculty of Health, Sport and Science, University of Glamorgan, Pontypridd, CF37 1DL; ${ }^{3}$ Professor of Paediatric Dentistry, ${ }^{4}$ Dean, School of Dentistry/Professor of Dental Public Health, Dental Health and Biological Sciences, School of Dentistry, Cardiff University, Heath Park, Cardiff, CF14 4XY

*Correspondence to: Dr Paul Gill

Email:PWGill@glam.ac.uk

\section{Refereed Paper}

DOI: 10.1038/bdj.2008.149

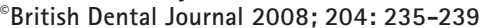

awareness and understanding of qualitative research, when its use is appropriate and what it can offer the profession, is relatively limited.

Yet qualitative methods, such as interviews, can offer dentistry a unique insight into peoples' personal perspectives, providing a more comprehensive understanding of their beliefs, knowledge and attitudes as well as offering greater depth and methodological flexibility than quantitative research methods such as structured questionnaires.,4

This series of papers will, therefore, introduce the readership to qualitative research, focusing on methods of data collection, conducting interviews with children and data analysis. It would be impossible within the scope of one paper to synthesise the entire literature on the methodologies discussed in the series, but it does offer an introduction to the issues researchers need to engage with in order to capitalise on this set of research approaches.

\section{QUANTITATIVE AND QUALITATIVE APPROACHES TO RESEARCH}

Quantitative research has traditionally dominated much of healthcare research, particularly dentistry. However, qualitative approaches, which are common within social sciences, are also recognised as equally important to healthcare enquiry. Both approaches have a place in healthcare research because they are each capable of addressing different research questions and therefore contributing to different aspects of clinical practice. ${ }^{5,6}$

For example, quantitative research provides quantified answers to research problems and is commonly associated with positivistic (objectively measurable), experimental research. ${ }^{3}$ Quantitative research approaches are frequently used to establish cause and effect relationships, the incidence of disease, to test experimental hypotheses, determine the effectiveness of interventions or treatments (eg brushing techniques), or for determining the opinions, attitudes or practices of a large population (eg how often people attend their dental practice). . $^{3,7}$

Conversely, qualitative research does not seek to provide quantified answers to research questions and tends to be associated with more naturalistic (ie research conducted in more 'natural settings', such as at home or work, as opposed to in a laboratory) types of research. ${ }^{3}$ Qualitative approaches are commonly used to explore, interpret, or obtain a 'deeper understanding' of certain aspects of human beliefs, attitudes or behaviour, such as people's personal experiences and perspectives (eg factors that influence their attendance with their GDP). ${ }^{4,7}$ Such approaches are therefore ideally suited to research where little is already known or understood, or 
to access areas that, because of their personal or unique nature, are generally not amenable to quantitative approaches such as structured questionnaires ${ }^{6,8}$ (eg exploring areas in which conventional questionnaires lack subtlety, breadth or depth, even when open-ended questions are used). Qualitative methods can also overcome literacy problems and are, therefore, particularly useful in obtaining detailed information directly from minors and/or those who have problems reading or writing.

As well as being a useful standalone method, qualitative methods can be used at various stages of the research process and for a variety of purposes. They can be very effective at the start of a project to develop hypotheses in newly emerged or under-researched areas, which can then be tested using quantitative measures in a later stage. Qualitative methods may be used to explore the meaning of existing quantitative data in more detail, especially when data is conflicting or unexpected. Qualitative methods may also be useful in the evaluation of perceptions of programmes (eg oral health initiatives), services, products or treatments. ${ }^{1,9,10}$

These uses are neither exhaustive nor mutually exclusive. Furthermore, neither qualitative nor quantitative research approaches are necessarily superior to the other. The appropriateness of the chosen approach depends on its ability to address the research problem. However, the value and potential of qualitative methods, such as interviews, have yet to be fully realised by the dental profession, even in studies where their use would appear to be particularly relevant.

\section{TERMINOLOGY USED IN QUALITATIVE RESEARCH}

Terminology and phrases used in qualitative work are often somewhat different to those used in quantitative research. Table 1 provides an overview and concise definition of common phraseology.

\section{METHODS OF DATA COLLECTION}

Methods of data collection used in qualitative research differ from those used in quantitative research because of a fundamental epistemological difference which underpins qualitative and quantitative methodologies. Epistemologies inform all understandings of methodologies. While methodology refers to the strategies and procedures of collecting data, epistemology deals with philosophical questions of what can be known, who can know it, and how the testing of beliefs in order to accept them as truth is approached. ${ }^{11}$ 'Epistemology is the science of knowing; methodology (a subfield of epistemology) might be called "the science of finding out". ${ }^{12}$

Quantitative research is based on an epistemological stance whereby research proceeds in a scientific, objective and value-free way to enumerate generalisable findings. Qualitative epistemologies, on the other hand, focus on social meanings, and the methodologies utilised aim to access these social meanings. It is crucial to understand that this epistemological difference lies between qualitative and quantitative methodologies: to judge qualitative research against a quantitative epistemology misses the value in the knowledge qualitative data can produce.

Methods commonly used involve observing human behaviour and interaction or conversing with people about their views, beliefs or actions. The most common methods of data collection used in qualitative research are briefly discussed here, but, particularly in healthcare settings, are focus groups and research interviews. These two methods are discussed in more detail in the second paper of this series.

\section{Observation}

In social research, observation is the systematic watching of people and events to find out about behaviours and interactions in natural settings. The researcher is the research instrument, engaged in watching, joining in and talking, in order to study every day settings. ${ }^{3,13}$ The level of participation a researcher has in the environment they are studying varies, and may be determined by how conspicuous any attempts to simply observe are in any given setting. In participant observation, they have a recognised role (other than researcher) in the setting in addition to their observer role, ${ }^{3}$ while in other settings the researcher will observe without participation in the activities of the setting. For example, an observation of a busy surgery waiting room would arguably attract less attention than an observation in a dental consultation, where there are fewer people and each has a defined, interacting role.

How overt the observer role is also varies: covert observation (however participatory) involves greater ethical concerns, most clearly relating to informed consent, particularly among vulnerable groups such as junior staff or patients whose participation has been allowed by 'gatekeepers'. ${ }^{14}$ While overt observation involves fewer ethical issues, it does risk the group reacting to the knowledge that they are being observed and behaving differently as a result. ${ }^{13}$

Gaining access to sites to conduct observation can be problematic and, once achieved, gaining sufficient rapport to facilitate the research can pose further difficulties. For example, in medical settings negotiations with different staff groups with different priorities and interests are required. The researcher must also be wary of the difficulties of becoming too involved or immersed in the setting ('going native') and losing sight of their research agenda. ${ }^{13}$ As with ethnographic studies more generally, observation is time consuming, labour intensive and costly, ${ }^{14}$ but it does offer valuable insights in health research settings on issues otherwise inaccessible through other methods. It can help overcome discrepancies between what people say or think they do, and what they appear to do to others. For example, in dentistry, participant observation may be particularly useful in observing how dentists interact and behave with their patients.

Kleinknecht and Bernstein ${ }^{15}$ observed patients' behaviours in the waiting room and in the dental surgery but also used self-report questionnaires for the patients and dentists. Adults reporting high anxiety by questionnaire behaved differently in the waiting room, where they felt free to display signs of their anxiety, but behaved the same as the low anxiety group in the dental surgery. ${ }^{15}$ This study not only demonstrates the value of observation data, but also shows how qualitative data can be used to enhance 


\begin{tabular}{|c|c|}
\hline Terminology & Definition \\
\hline Epistemology & Theories of knowledge that underpin how research proceeds. \\
\hline Methodology & $\begin{array}{l}\text { Theories of 'finding out', which determine the procedures } \\
\text { undertaken in research. }\end{array}$ \\
\hline Thematic content analysis & Organising qualitative data into emerging themes and concepts. \\
\hline Ethnography & $\begin{array}{l}\text { The systematic description of a cultural group's values, beliefs, descrip- } \\
\text { tions and perspectives, using various qualitative data collection methods. }\end{array}$ \\
\hline Grounded theory & $\begin{array}{l}\text { Using a systematic set of procedures to arrive at theory about } \\
\text { social processes from real world observations. }\end{array}$ \\
\hline Phenomenology & Exploring the lived experiences of participants. \\
\hline Rigour (concepts) & $\begin{array}{l}\text { Strategies used in qualitative research to maintain methodological rigour, } \\
\text { reduce the potential for bias and enhance the validity of research findings. }\end{array}$ \\
\hline
\end{tabular}

understandings of quantitatively collected data, as discussed earlier.

Originally, in the mid-1980s, Nettleton $^{16}$ identified a lack of qualitative work on perceptions in relation to oral health and began a series of studies using qualitative methods, including observations of dental visits in a surgery in South London. This work illuminated and theorised the dental visit in an entirely innovative way and facilitated the identification of new questions and hypotheses. Her monograph Power, pain and dentistry ${ }^{16}$ develops Foucault's concepts relating to the gaze and his concepts of power, to understand pain and fear in dentistry and draw parallels with these Foucauldian concepts in other settings.

\section{Qualitative interviews}

Interviewing in qualitative research is quite distinct from structured interviewing techniques, which require a schedule of questions with predetermined and unchanging wording, asked in a given order so that respondents all respond to identical stimuli. In qualitative interviews, the interviewer has a more passive, adaptive role, giving direction to topic areas. ${ }^{17}$ This level of direction varies in different qualitative interview approaches. Ethnographic interviews, which owe a major debt to cultural anthropology, are usually conducted on-site during field studies (involving observational methods) when an ongoing relationship has already been established with research participants. ${ }^{18}$
However, practical constraints due to time, research agendas, financing and access mean that semi-structured qualitative interviews are more often used in research in healthcare settings. These less structured interview methods are valuable in researching issues that research populations may not be comfortable or familiar with verbalising. Talking about health behaviours and their understandings and interpretations can be done in a way that allows the expression of relevant and representative issues. Relevant data becomes more forthcoming as confidence in and comfort with talking about the subject matter grows, ${ }^{19}$ and interviews should provide an atmosphere in which participants are more willing to be open about behaviours and attitudes that they may be reluctant to admit to in other circumstances.

Such interviews can offer a rich source of data on how people account for both good and bad experiences, ${ }^{20}$ reporting these experiences according to their own priorities, understandings and interpretations. The guiding principle of the conduct of less structured interviews should be that they identify the subjects to be covered, rather than the questions to be asked, ${ }^{21}$ so allowing researchers to cover predetermined research questions and encourage unknown issues to emerge from the research participants.

Nettleton's ethnography of dental health beliefs included unstructured interviews with mothers of young children, throwing new light on dental health issues. ${ }^{22}$ The interviews demonstrated widespread negative feelings of parental guilt displayed by all of the women interviewed in relation to their child's oral health, which emerged from the data and had not been anticipated. ${ }^{22}$ More recently, Gussy et al. ${ }^{23}$ combined interview and focus group work with primary healthcare professionals and identified important and unforeseen issues relating to barriers to the development of an integrated shared approach to caries prevention in young children. ${ }^{23}$

\section{Group methods}

The most commonly used group method in social research is the focus group. A focus group can be defined as a group discussion on a given topic organised for research purposes. This discussion is guided, monitored and recorded by a researcher (sometimes called a moderator or facilitator). Focus groups are used for the generation of information on collective views and the meanings that lie behind those views. Being a qualitative method, focus groups are also useful in generating a rich understanding of research participants' experiences and beliefs. ${ }^{24,25}$ In dentistry, focus groups may be of particular use in, for example, exploring dentists' views of employment issues or treatment choices and preferences.

For the purposes of clarity, it is useful to distinguish the focus group from other group research methods which may have some similar characteristics, but which should not be confused with focus groups: ${ }^{26}$

\section{Nominal group technique. Group} members may not meet and do not interact directly, but are interviewed individually and their responses fed back to other participants. This technique can be useful when convening a group is hard (for example with research involving specialist, or geographically diverse populations), to avoid participants being influenced by strong views or dominant members, or where conflict may interfere with a discussion

2. Delphi technique. A method for predicting trends in a particular phenomenon. A panel of experts is convened and asked to provide a 
forecast of events. These predictions are summarised and circulated to the panel who revise their forecasts, and this process repeated until either a consensus emerges or no new revisions are made. Again, the group does not meet face to face

3. Brainstorming and synectics. These two methods differ, but both are designed to facilitate creativity and generate new ideas rather than identify views, norms and processes. Brainstorming is more creative and un-moderated than the more structured generation of ideas in synectics

4. Leaderless discussion groups. This method is used when the dynamics of the group are the focus of interest rather than the topic under discussion. It provides a way of assessing how an individual can give direction and get results in organisation and team situations. Discussions are un-moderated, and the emergence of leaders can be a useful outcome of the process. ${ }^{26}$

\section{Diaries and documents}

Less used but also valuable in health research settings are methods involving documents that have been either solicited for the purposes of the research (eg participants keeping a diary or writing an account specifically for the research), or documents which already existed (such as text books or magazines). Asking research participants to keep diaries allows them to report on their own behaviour in the setting in their own way, using their own language and categories, without requiring the presence of the researcher. ${ }^{27}$ The time commitment required of participants when using this method can be onerous, and legibility issues may make data handling stages problematic. These methods have evolved to make use of recent developments in computer technologies, for both solicited (diary) approaches and unsolicited approaches (eg the analysis of websites or message boards). ${ }^{28}$

\section{SAMPLING}

Whether conducting interviews, focus groups or observation, how qualitative researchers choose their participants, and how many are sampled, is an important consideration. Statistical sampling methods used in survey methods are uncommon in qualitative research. The time consuming and costly nature of the methods renders probability sampling impractical, as well as it being epistemologically unnecessary in order to generate rigorous, valid findings. Instead, systematic non-probability methods are used to identify individuals with characteristics of relevance to the study, in order to facilitate the exploration of a particular aspect of behaviour. ${ }^{13}$ This range of sampling methods may be viewed with a degree of suspicion by researchers familiar with the principle of randomisation that lies at the heart of probability sampling methods. However, as the name suggests, these sampling strategies are systematic, based on set criteria designed to best select the most appropriate sample for a given project.

\section{RIGOUR}

In the field of health research there has been a strong biomedical tradition of quantitative and experimental methods, and consequently qualitative methods are sometimes thought to lack scientific rigour. Various strategies are available to protect against bias and enhance the reliability of qualitative research..$^{13}$ How this is achieved varies in detail between different qualitative approaches, but common issues are also identifiable. ${ }^{29}$

Checklists have become relatively common currency and do have their uses, but ultimately offer no substitute for a systematic and thorough application of the principles of qualitative research methodologies. The procedures commonly covered by such checklists include:

- Purposive sampling, to address bias concerns

- Grounded theory, to show original theorising in the work

- Multiple coding, to simulate interrater reliability (discussed further in paper 4)

- Triangulation, to confirm or refute internal validity

- Respondent validation, to confirm or refute interpretation of the data (discussed further in paper 4).

However, the checklists (and indeed the items on them when taken individually) all have limits in how well they can achieve their ostensible aims, and only an understanding of the principles of the methodology used will truly establish the rigour of a project. ${ }^{30}$ How these issues arise in qualitative research is discussed further in later papers in this series.

Mays and Pope $^{13}$ assert that qualitative researchers should provide detailed and transparent accounts of the study method and data in any reports or publications, that would allow another trained researcher to follow to the given conclusions, and the production of a plausible and coherent explanation of the phenomenon studied (our emphasis). Just like any good research.

\section{CONCLUSION}

Qualitative research methods, such as interviews, certainly have a place within dentistry, particularly for problem definition, hypothesis generation, evaluation and for exploring subject areas that are inadequately understood. ${ }^{13,14}$ However, qualitative approaches should also be regarded as valuable research methods in their own right and should not be thought of as merely a precursor for larger scale, quantitative research.

Qualitative research methods remain excellent ways of helping to identify peoples' thoughts, feelings, attitudes, perceptions and preferences. They differ, both philosophically and practically, from quantitative methods, but can also be used alongside those methods. They can produce unique, detailed, personal accounts, which can be used to improve our knowledge and understanding on a variety of issues that are of interest and importance to dentistry. However, to ensure that qualitative studies are constructive and methodologically rigorous it is essential that researchers using these approaches are appropriately trained and experienced.

The following three papers in this series explore methods of data collection in more detail, focusing on research interviews and focus groups, conducting research interviews with children and analysing and presenting qualitative data.

1. Blinkhorn A S, Leathar D S, Kay E J. An assessment of the value of quantitative and qualitative data collection techniques. Community Dent Health 1989; 6: 147-151. 
2. Watt R. Introduction. In Fuller S S, Watt R (eds) Using qualitative and quantitative research to promote oral health. pp 1-2. Manchester: Eden Biacki Press, 1992.

3. Pope C, Mays N. Reaching the parts other methods cannot reach: an introduction to qualitative methods in health and health service research. BMJ 1995; 311: 42-45.

4. Silverman D. Doing qualitative research. London: Sage Publications, 2000.

5. Polit D F, Hungler B P. Nursing research. 3rd ed. Philadelphia: J B Lippincott, 1993.

6. Britten N. Qualitative interviews in healthcare. In Pope C, Mays N (eds) Qualitative research in health care. 2nd ed. pp 11-19. London: BMJ Books, 1999.

7. Greenhalgh T, Taylor R. Papers that go beyond numbers (qualitative research). BMJ 1997; 315: 740-743.

8. Pope C, Mays N (eds). Qualitative research in health care. 2nd ed. London: BMJ Books, 1999.

9. Blinkhorn A S. Qualitative research - does it have a place in dental public health? J Public Health Dent 2000; 60: 3-4.

10. Chestnutt / G, Robson K F. Focus groups - what are they? Dent Update 2002; 28: 189-192.
11. Harding S. Is there a feminist method? In Harding $S$ (ed) Feminism and methodology: social science issues. Milton Keynes: Open University Press, 1987.

12. Babbie E. The practice of social research. 6 th ed. Belmont: Wadsworth, 1992

13. Mays N, Pope C. Qualitative research: rigour and qualitative research. BMJ 1995; 311: 109-112

14. Savage J. Ethnography and health care. BMJ 2000; 321: 1400-1402.

15. Kleinknecht R A, Bernstein D A. The assessment of dental fear. Behav Ther 1978; 9: 626-634.

16. Nettleton S. Power, pain and dentistry. Buckingham: Open University Press, 1992.

17. Smith H W. Strategies of social research. Milton Keynes: Open University Press, 1975

18. Sherman Heyl B. Ethnographic interviewing. In Atkinson P, Coffey A, Delamont S, Lofland J, Lofland L (eds) Handbook of ethnography. pp 369 383. London: Sage, 2001.

19. Brannen J. The study of sensitive subjects. Sociol Rev 1988; 36: 552-563.

20. Silverman D. Interpreting qualitative data. London: Sage, 1993.

21. Hammersley M, Atkinson P. Ethnography: principles in practice. 2nd ed. London: Routledge, 1995

22. Nettleton S. Understanding dental health beliefs. Br Dent J 1986; 161: 145-147.

23. Gussy M G, Waters E, Kilpatrick M. A qualitative study exploring barriers to a model of shared care for pre-school children's oral health. Br Dent $J$ 2006; 201: 165-170.

24. Kitzinger J. The methodology of focus groups: the importance of interaction between research participants. Sociol Health IIIn 1994; 16:103-121.

25. Morgan D L. The focus group guide book. London: Sage Publications, 1998.

26. Stewart D W, Shamdasani P M. Focus groups. Theory and practice. London: Sage Publications, 1990.

27. Babbie E. Survey research methods. Belmont, California: Wadsworth, 1990.

28. Mann C, Stewart F. Internet communication and qualitative research. London: Sage, 2000.

29. Maggs-Rapport, F. 'Best research practice': in pursuit of methodological rigour. J Adv Nurs 2001; 35: 373-383.

30. Barbour R. Checklists for improving rigour in qualitative research: a case of the tail wagging the dog? BMJ 2001; 322: 1115-1117. 